\title{
FIJACIÓN DE DOCTRINA POR EL TRIBUNAL SUPREMO SOBRE EL DÍA INICIAL PARA EL CÓMPUTO DEL PLAZO EN LA RECLAMACIÓN DE DAÑOS POR UNA ASISTENCIA MÉDICA DEFICIENTE
}

\author{
LETICIA LATORRE LUNA \\ Abogada y doctoranda de la Universidad de Murcia \\ leticia.latorrel@um.es
}

STS DE LA SALA 3. ${ }^{\text {a }}$ DE 4 DE ABRIL DE 2019

N. ${ }^{\circ}$ SENTENCIA: 463/2019. N. ${ }^{\circ}$ RECURSO: $4399 / 2019$

CENDOJ: (ROJ: STS 1137/2019 - ECLI:ES:TS:2019:1137)

PALABRAS CLAVE: responsabilidad patrimonial, Administración Pública, acción de indemnización, prescripción, plazo de un año, daños físicos o psíquicos, cómputo, dies a quo, secuelas, conocimiento afectado, independencia del expediente incapacidad laboral.

KEYWORDS: patrimonial responsibility, Public Administration, compensation action, prescription, one year term, physical or mental damages, computation, dies a quo, sequelae, affected knowledge, independence of the file, incapacity for work.

La importancia jurídica de la presente sentencia radica sustancialmente en que a través de la misma el Tribunal Supremo asienta una base doctrinal en relación a la fecha de inicio del cómputo del plazo para reclamar daños a causa de una asistencia médica defectuosa. En suma, como se podrá apreciar en el presente comentario, el Alto Tribunal establece que el "dies a quo" es el de la curación o estabilización del enfermo.

La Sala Tercera, de lo Contencioso-Administrativo del Tribunal Supremo conoce del recurso de casación número 4399/2017 interpuesto por un paciente que sufrió el día 10 de octubre de 2010 un accidente laboral (tirón en la espalda), quien tras estar durante aproximadamente dos años en tratamiento farmacológico y de fisioterapia, en fecha 10 de enero de 2012 fue intervenido quirúrgicamente en la Unidad de Columna del Hospital Central Fraternidad Muprespa en Madrid, sufriendo, a consecuencia de la intervención, el desgarro de vena ilíaca propiciándole una Trombosis Venosa Profunda, siendo posteriormente ingresado de nuevo tres veces durante el año 2012. 
Finalmente, en fecha 31 de enero de 2013, el Instituto Nacional de la Seguridad Social dicta resolución donde reconoce lesiones permanentes no invalidantes, resolución que fue anulada por sentencia de 9 de abril de 2014 dictada por el Juzgado de lo Social núm. 2 de Oviedo, que declara la situación de Incapacidad Permanente Total del paciente para su profesión habitual de montador de instalaciones eléctricas. De igual modo, en fecha 23 de marzo de 2015 (dos años y dos meses después de la resolución del INSS) el paciente formula reclamación de responsabilidad patrimonial contra la Mutua Muprespa por defectuosa asistencia sanitaria de sus servicios médicos que le generó una incapacidad permanente total para su profesión.

En concreto, la cuestión planteada al Alto Tribunal en el recurso de casación $\mathrm{n}^{\circ}$ 4399/2017 del que dimana la sentencia objeto de análisis, es la del interés casacional objetivo para la formación de jurisprudencia a efectos de determinar si en el supuesto de reclamaciones de responsabilidad patrimonial por secuelas derivadas de un accidente o de una prestación sanitaria defectuosa que genere una incapacidad laboral, si el "dies a quo" del plazo de un año para reclamar es:

1. Bien, a partir de la fecha en la que se estabilizan definitivamente las secuelas, con conocimiento del afectado, tal y como sostiene la jurisprudencia de la Sala Tercera, de lo Contencioso-Administrativo del Tribunal Supremo, o bien;

2. en la fecha en la que se declara la incapacidad laboral como consecuencia de las secuelas por resolución administrativa, o, en su caso, por sentencia firme del Orden Social, como viene manteniendo la Sala Primera, de lo Civil del Alto Tribunal.

En el fondo lo que se pretende en el citado recurso es que el Tribunal Supremo realice una interpretación unánime y objetiva del artículo 142.5 de la Ley 30/92 (art. 67.1 de la Ley 39/15) a fin de concretar el momento en el que prescribe el plazo de un año a efectos de formular reclamación de responsabilidad patrimonial, debido a los diferentes criterios jurisprudenciales sostenidos por órganos de distinto orden jurisdiccional, de lo que se desprende el interés casacional objetivo para la formación de jurisprudencia.

Así pues, la parte recurrente alega fundamentalmente la vulneración del principio de "Actio Nata" como principal criterio aplicado por la doctrina del Tribunal Supremo en la interpretación del artículo 142.5 de la Ley 30/1992, por el que se deriva que el plazo de prescripción anual para el ejercicio de la acción de responsabilidad patrimonial comienza desde el momento en que el perjudicado tiene conocimiento fehaciente de la exacta dimensión y entidad del daño causado, que es cuando se dicta resolución administrativa o judicial, reconociendo o denegando la incapacidad interesada.

Por otro lado, las partes contrarias, esto es, FRATERNIDAD MUPRESPA, y de ZURICH INSURANCE PLC, se oponen al recurso fundamentando sus argumentos en base a dos alegaciones principales: en primer lugar anuncian que en el presente caso no nos encontramos ante un supuesto de casación para unificación de doctrina, sino en todo caso, ante una situación de interés casacional objetiva a fin de formar jurisprudencia, o de ratificar, rectificar o modular la existente, en concreto, en el presente caso debido a la posible entre las sentencias dictas por la Sala primera y la Sala tercera del Tribunal Supremo.. En segundo lugar, se alega de contrario, que la sentencia recurrida aplica la doctrina uniforme de la Sala Tercera en la que se entiende que cuando la situación física que acredita la declaración de incapacidad esté determinada previamente no extenúa el cómputo del plazo de prescripción. 
Por último, el letrado de los Servicios Jurídicos del INSS, se opone al recurso alegando fundamentalmente su falta de legitimación pasiva, debido a que el INSS es un organismo publico ajeno a la asistencia sanitaria prestada por la Mutua, que aunque colabora con la Seguridad Social, está dotada de personalidad jurídica propia.

De ello resulta necesario alzar la cuestión de si realmente nos encontramos ante diferentes criterios jurisprudenciales sostenidos por órganos de distinto orden jurisdiccional acerca de la interpretación del artículo 142.5 de la Ley 30/92, esto es, ¿es cierto que la Sala de lo Civil y la Sala de lo Contencioso-administrativo del Alto Tribunal mantienen criterios interpretativos diferentes en relación al citado precepto legal, siendo necesaria, por consiguiente, la formación de jurisprudencia al respecto? Según aclara la sentencia objeto de estudio, de un lado, la Sala tercera, de lo Contencioso-administrativo del Tribunal Supremo mantiene que cuando en la fecha del Alta definitiva constan estabilizadas las lesiones y concretadas las secuelas, o bien consta determinado en toda su dimensión el daño personal y los conceptos objeto de indemnización, es cuando se entiende que el perjudicado tiene conocimiento del daño sufrido y por ende, es la fecha que determina el momento en el que comienza el plazo de prescripción. De otro lado, la Sala Primera, de lo Civil, mantiene que en caso de lesiones que no consten concretadas en el Alta médica definitiva requiriéndose de una resolución posterior a fin determinarse las secuelas de incapacidad permanente causadas en un hecho generado de responsabilidad civil extracontractual, el plazo anual de prescripción es el momento en el que se dicte resolución firme (administrativa o judicial) en la que se concrete el grado de invalidez, y no en la fecha de alta, al ser realmente el momento de la resolución firme cuando el perjudicado tiene pleno conocimiento de la entidad de los perjuicios causados.

Luego entonces, el Alto Tribunal, entiende que ambas doctrinas asentadas tanto por el orden jurisdiccional civil como por el contencioso-administrativos son compatibles, a consecuencia de el "dies a quo" del plazo de un año para reclamar sería la fecha en la que se declara la incapacidad laboral como consecuencia de las secuelas por resolución administrativa o sentencia firme, siempre y cuando en la fecha del Alta definitiva no consten estabilizadas definitivamente las secuelas sufridas por el perjudicado, puesto que hasta ese momento el mismo no ha conocido de la totalidad del alcance del daño. Por tanto, el "dies a quo" del plazo de prescripción anual ha de fijarse en la fecha del informe en el que quede definitivamente fijadas las secuelas, en primer lugar, si así constan en el Alta médica definitiva y, en su defecto, en la fecha posterior de la que conste la resolución firme (administrativa o judicial).

Así pues, en la presente causa, nos encontramos ante daños derivados de la actuación médica pública cuyo procedimiento a seguir a efectos de reclamar una indemnización es el de la vía de responsabilidad patrimonial, procedimiento en el que no se entran a valorar las consecuencias laborales de las secuelas sufridas, puesto que para su valoración se ha de acudir a la vía de reclamación de incapacidad laboral y resarcimiento a través de las correspondientes prestaciones de la Seguridad Social, siendo en todo caso compatibles ambas vías en virtud del principio de la plena indemnidad o de la reparación integral.

Por ende, según señala el Tribunal Supremo, nos encontramos ante dos tipos de reclamaciones diferentes (reclamación de responsabilidad patrimonial y reclamación de incapacidad laboral) que derivan del mismo supuesto de hecho, pero con distintas consecuencias jurídicas, ya que, de un lado, la finalidad de la reclamación de responsabilidad patrimonial es la obtención de una indemnización de los perjuicios generados por la asistencia médica defectuosa prestada por los servicios públicos sanitarios o entidad colaboradora con los mismos, como una mutua, cuya indemnización será cuantificada en atención al perjuicio generado y sus secuelas, que en la presente causa fue determinado en el informe médico de fecha 8 de octubre de 2012 
emitido por el Dr. Alexander, cuando concluye que "el paciente nunca estaría capacitado para volver a desarrollar su trabajo como montador en instalaciones eléctricas ni esfuerzos aún livianos", de lo que se desprende su incapacidad absoluta, sin ser necesario una declaración formal previa de incapacidad seguida en procedimiento (administrativo o judicial) de reclamación de incapacidad laboral.

En definitiva, el Alto Tribunal concluye que el criterio interpretativo del art. 142.5 de la Ley 30/92 (67.1 de la Ley 39/15) para fijar el "dies a quo" para el cómputo del plazo anual de prescripción de una reclamación de responsabilidad patrimonial por daños (físicos o psíquicos) es el de la fecha de la curación o determinación de las secuelas, con conocimiento del perjudicado, indistintamente y, al margen de que de manera independiente se siga expediente de incapacidad laboral por medio de reclamación formulada en vía administrativa (ante la Seguridad Social u organismo anexo) o judicial (ante el Juzgado de lo Social). En suma, la fecha de prescripción anual del artículo 142.5 de la Ley 30/92, la va a marcar la fecha del documento (informe médico o, en su defecto, la posterior resolución administrativa o judicial firme) que ponga en conocimiento preciso del afectado la entidad de las secuelas y de los perjuicios irrogados.

Por último, a modo de curiosidad cabe destacar que la problemática de saber cuándo empiezan a contarse los plazos para la prescripción, desde antaño ha prevalecido para los juristas la teoría de la "actio nata", de Savigny, que mantiene que el término de las prescripciones no empieza a correr hasta el momento que ha nacido la acción y pueda ejercitarse. Tan evidente resulta su aplicación, que nuestro propio Código Civil la recoge en el artículo 1.969 a establecer que "el termino para la prescripción de toda clase de acciones, cuando no haya disposición especial que otra cosa determine, se contará desde el día en que pudieron ejercitarse." Por ende, la cuestión jurídica radica en la precisión de concretar cuándo nace la acción, esto es, cuándo se puede ejercitar en vía jurídica o administrativa, que en el caso de reclamación de daños por una asistencia médica defectuosa, el Alto Tribunal ha fijado doctrina por medio de la sentencia analizada, estableciendo que el "dies a quo" del plazo anual comienza desde la fecha de curación o estabilización de las secuelas, con conocimiento del perjudicado. 